
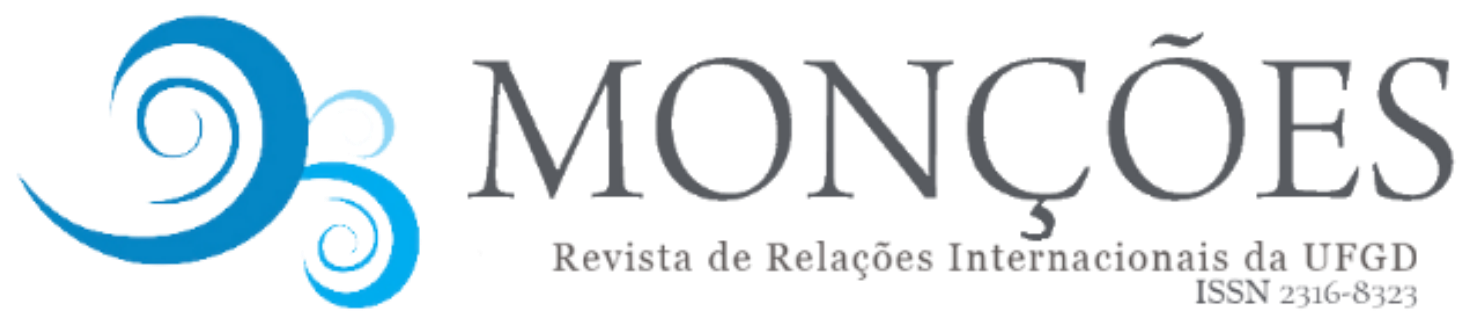

Revista de Relações Internacionais da UFGD

ISSN 2316-8323

\title{
OS 'LUGARES' DA AMAZÔNIA NAS RELAÇÕES INTERNACIONAIS: (RE)PENSANDO AS RI A PARTIR DO ENCONTRO AMAZÔNIA CENTRO DO MUNDO
}

\author{
LUCAS GUERRA \\ Doutorando e Mestre em Relações Internacionais pela Pontifícia Universidade Católica do \\ Rio de Janeiro (IRI/PUC-Rio), Rio de Janeiro (RJ), Brasil. \\ ORCID: https://orcid.org/0000-0002-2248-2544 \\ lucaspxguerra@gmail.com
}

\begin{abstract}
RESUMO: No artigo, propõe-se um duplo objetivo. De um lado, questiona-se "quais os lugares da Amazônia nos estudos de RI no Brasil?". De outro, inquirimos sobre o potencial de repensar pressupostos da disciplina a partir de um evento recente transcorrido na Amazônia: o Encontro Amazônia Centro do Mundo. Para responder à primeira pergunta, sistematizamos produções acadêmicas em RI apresentadas/publicadas nos três últimos Encontros Nacionais da Associação Brasileira de Relações Internacionais (ABRI) e nas revistas Carta Internacional, Contexto Internacional e Revista Brasileira de Política Internacional. Organizamos os resultados obtidos em termos de: (1) alocação nas Áreas Temáticas da ABRI; (2) divisões temáticas em categorias por nós identificadas; (3) produções por região geográfica do Brasil e (4) divisões temáticas por região geográfica. A partir do que observamos sobre o estado da arte em estudos de Amazônia nas RI no Brasil, propomos uma "outra inscrição" da Amazônia na disciplina a partir do Encontro Amazônia Centro do Mundo (EACM) e das perspectivas e reivindicações dos "povos da floresta" ali articuladas. Sob essa base, apresentamos uma breve reflexão crítica sobre os conceitos de "poder" e "resistência" nas RI, e concluímos apontando o potencial do EACM para se pensar nas potencialidades de uma "cosmopolítica da Amazônia".
\end{abstract}

PALAVRAS-CHAVE: Amazônia; Relações Internacionais; cosmopolítica.

\section{LOS 'LUGARES' DE LA AMAZONÍA EN LAS RELACIONES INTERNACIONALES: (RE) PENSANDO LAS RRII DESDE EL ENCUENTRO AMAZONÍA CENTRO DEL MUNDO}

RESUMEN: En el artículo se propone un doble objetivo. Por un lado, la pregunta es "¿cuáles son los lugares de la Amazonía en los estudios de RRII en Brasil?". Por otro lado, preguntamos sobre la posibilidad de repensar los presupuestos de la disciplina a partir de un evento reciente que tuvo lugar en la Amazonía: el Encuentro Amazonía Centro del Mundo. Para responder a la primera pregunta, sistematizamos producciones académicas en RRIl presentadas en los últimos tres Encuentros Nacionales de la Asociación Brasileña de Relaciones Internacionales (ABRI) y en las revistas Carta Internacional, Contexto Internacional y Revista Brasileira de Política Internacional. Organizamos los resultados obtenidos en términos de: (1) asignación en las áreas temáticas de $A B R I$; (2) divisiones temáticas en categorías identificadas por nosotros; (3) producciones por región geográfica de Brasil y (4) divisiones temáticas por región geográfica. Con base en lo que observamos sobre el estado del arte en los estudios de la Amazonia en las RRII en Brasil, proponemos una "otra inscripción" de la Amazonía en la disciplina a partir del Encuentro Amazonía Centro do Mundo (EACM) y de las perspectivas y demandas de los "Pueblos de la selva" que fueran allí articulados. Sobre esta base, presentamos una breve reflexión crítica sobre los conceptos de "poder" y "resistencia" en las RRII, y concluimos señalando el potencial del EACM para pensar en el potencial de una "cosmopolítica de la Amazonía".

PALABRAS-CLAVE: Amazonía; Relaciones Internacionales; Cosmopolítica 


\title{
THE 'PLACES' OF THE AMAZON IN INTERNATIONAL RELATIONS: (RE) THINKING IR FROM THE MEETING AMAZÔNIA CENTRO DO MUNDO
}

\begin{abstract}
In this paper, we have a double-fold objective. On the one hand, we ask: "what are the 'places' of the Amazonia in IR studies in Brazil?". On the other hand, we asked about the potential to rethink some assumptions of the discipline based on a recent event, the Meeting Amazônia Centro do Mundo. To answer the first question, we systematized academic productions in IR presented/published in the last three National Meetings of the Brazilian Association of International Relations (ABRI) and in the journals Carta Internacional, Contexto Internacional and Revista Brasileira de Política Internacional. We organize the results obtained in terms of: (1) allocation in ABRI's thematic areas; (2) thematic divisions in categories identified by us; (3) productions by geographic region of Brazil and (4) thematic divisions by geographic region. Based on what we observed about the studies of Amazonia in Brazilian IR, we propose an "other inscription" of Amazonia in the discipline from the Amazônia Centro do Mundo Meeting (EACM) and the perspectives and demands of the "peoples of the forest" articulated there. On this basis, we present a brief critical reflection on the concepts of "power" and "resistance" in IR, and conclude by pointing out the potentialities of the EACM to think about the potential of a "cosmopolitics from Amazonia".
\end{abstract}

KEYWORDS: Amazon; International Relations; cosmopolitics.

\section{Introdução}

No presente artigo, temos um duplo objetivo. De um lado, pretendemos trazer uma breve sistematização de parte da produção acadêmica sobre Amazônia nas Relações Internacionais (RI) do Brasil. Nos perguntamos, nesse sentido, "quais são os 'lugares' que a Amazônia tem ocupado nos trabalhos na disciplina?". De outro lado, propomos também uma reflexão a respeito "do que significa pensar as $\mathrm{Rl}$ a partir da Amazônia?", à qual desenvolvemos a partir de uma breve análise de um evento específico: o Encontro Amazônia Centro do Mundo (EACM), realizado nas imediações de Altamira - PA em novembro de 2019.

Para responder a ambas as perguntas, nos baseamos em uma metodologia essencialmente qualitativa, baseada na revisão bibliográfica principalmente dos estudos sobre a Amazônia nas RI no Brasil, mas também de trabalhos sobre Amazônia em outras áreas de conhecimento e sobre a disciplina de Relações Internacionais. Mais especificamente, para responder à primeira pergunta, fizemos uma sistematização dos 28 (vinte e oito) trabalhos que foram apresentados/publicados sobre a Amazônia nas três últimas edições do Encontro Nacional da Associação Brasileira de Relações Internacionais (ABRI) e em três importantes periódicos da disciplina no Brasil: Carta Internacional, Contexto Internacional e Revista Brasileira de Política Internacional. Para responder à segunda questão, dado o caráter recente e relativamente 'isolado' do EACM, nos baseamos sobremaneira em relatos de 
jornalistas que estiveram presentes no Encontro, bem como no Manifesto que resultou dele. A isso, somamos algumas considerações teóricas sobre "poder" e "resistência" nas Relações Internacionais, duas das questões da disciplina que argumentamos que podem ser (re) pensadas a partir da Amazônia.

$\mathrm{O}$ artigo se encontra dividido em duas seções principais. Na primeira delas, apresentamos nossas considerações a respeito dos 'lugares' da Amazônia nos estudos de RI no Brasil, considerando quatro categorias, à saber: (1) as áreas temáticas da $\mathrm{ABRI}$; (2) as divisões temáticas que identificamos em nossa revisão bibliográfica; (3) as regiões geográficas da produção acadêmica sobre o tema; e (4) a divisão temática por região. Na segunda seção, propomos uma "outra inscrição" da Amazônia nos estudos brasileiros de RI, a partir de reflexões sobre o Encontro Amazônia Centro do Mundo (EACM). Para fins didáticos, dividimos o Encontro em duas partes, às quais correspondem duas subseções. Na primeira delas, apresentamos o Encontro na Terra do Meio e, a partir dele, a importância do "evento" (STENGERS, 2018) nas Relações Internacionais. Na segunda, introduzimos o Amazônia Centro do Mundo e seu Manifesto, e a partir desse ponto apresentamos algumas reflexões sobre os potenciais de "pensar as RI a partir da Amazônia" (PICQ, 2016) no Brasil.

\section{Os 'lugares' da Amazônia nos estudos de Relações Internacionais no Brasil}

O que aqui entendemos por "Amazônia" diz respeito a uma vasta região transfronteiriça de imensa riqueza natural, social, histórica e cultural, cuja característica em comum é ser atravessada pela maior floresta tropical do mundo: a Floresta Amazônica. Trata-se de "uma extensa floresta tropical úmida, com uma área equivalente a 8 milhões de $\mathrm{km}^{2}$ ", e que abrange oito países soberanos: Bolívia, Brasil, Colômbia, Equador, Guiana, Peru, Suriname e Venezuela, além do 'território francês' da Guiana Francesa (PORTO-GONÇALVES, 2015, p. 64). Em alguns países, como Brasil e Peru, a região de Floresta Amazônica ocupa mais de 50\% da extensão de seus territórios, com incomensuráveis riquezas minerais, animais e vegetais (ARAGÓN, 2011, p. 76).

A região possui ainda o maior banco genético entre todos os ecossistemas da Terra: "em apenas um hectare da Amazônia existem mais espécies vivas do que em todas as florestas do mundo temperado. E no hectare vizinho as espécies não são 
necessariamente as mesmas" (PORTO-GONÇALVES, 2015, p. 65). A concentração de cerca de 1/6 de toda a água doce do planeta na Bacia Amazônica, a maior bacia hidrográfica do mundo, completa o rol de riquezas naturais da região (ibid.).

A essa vastidão de riquezas naturais, soma-se ainda a imensa riqueza humana, histórica e cultural da Amazônia. Como lembra Carlos Porto-Gonçalves (2015, p. 66), ao contrário do que versam narrativas da Amazônia enquanto "deserto demográfico", a região é ricamente habitada ao menos desde os últimos 11.200 anos. Estima-se que 29 milhões de pessoas habitam a região, cerca de 10\% da soma das populações dos países que a compõem (ARAGÓN, 2011, p. 77). Dentre essas pessoas, encontramse centenas de etnias indígenas, muitas comunidades quilombolas e reservas extrativistas $^{1}$ de seringueiros, açaizeiros, dendezeiros, quebradeiras de babaçu, pescadores, pequenos agricultores, entre outros "povos da floresta" ${ }^{2}$ que têm na Amazônia a sua fonte de subsistência (PORTO-GONÇALVES, 2017, p. 159).

Essa breve apresentação à ampla região que aqui entendemos por "Amazônia" já coloca em evidência como nela se manifestam diversas questões de importância central às Relações Internacionais. Para perspectivas mais tradicionais nos estudos da disciplina, deveria chamar a atenção a importância geopolítica da Amazônia, por sua imensa riqueza em recursos estratégicos para o poder dos Estados e promoção do desenvolvimento (PENNA FILHO, 2013, p. 98-103). Ainda nessas perspectivas, destaca-se o potencial da região amazônica para o comércio internacional, tanto por suas riquezas inexploradas quanto pelas oportunidades de investimentos em infraestrutura para a conexão do subcontinente sul-americano e sua vinculação a rotas do comércio global (WEGNER; FERNANDES, 2018, p. 369-373).

Há ainda a importância da região em termos de cooperação internacional. Com efeito, a região possui a sua própria organização de integração regional: a Organização do Tratado de Cooperação Amazônica (OTCA), fundada em 1995. Além disso, a Amazônia é peça central em um dos temas fundamentais na agenda global

\footnotetext{
${ }^{1}$ As Reservas Extrativistas (RESEX) são espaços territoriais concedidos pelo poder público para comunidades extrativistas tradicionais, como as acima mencionadas, para que sigam realizando ali suas atividades econômicas e modos de vida, de maneira sustentável (MELLO, 1996, p. 315).

${ }^{2}$ Utilizamos o termo para nos referir a todos os povos, grupos, comunidades e etnias que vivem na Floresta, com ela experenciam seus modos de vida e dela retiram o seu sustento material. Referenciamos, assim, a importante figura histórica do ativista e seringueiro Chico Mendes, que tinha como princípio de luta a ideia de que "não existe defesa da floresta sem os povos da floresta" (PORTOGONÇALVES, 2017, p. 159).
} 
contemporânea - o das mudanças climáticas e preservação ambiental - o que lhe atribui grande potencial de projeção internacional, seja para os países que a compõem, seja para entidades subnacionais e transnacionais que atuam na região (DE WIT; FREITAS, 2019, p. 1-2).

Tendo em consideração esses elementos, resulta surpreendente que a Amazônia seja ainda um tema de estudos marginal na disciplina de Relações Internacionais (RI). Como Manuela Picq (2016, p. 1) registrou recentemente, a Amazônia tem sido fundamentalmente invisibilizada como espaço relevante para se pensar tanto nas $\mathrm{RI}$ enquanto disciplina quanto na política mundial de maneira geral. Picq (2016, p. 8) sustenta suas observações em uma análise dos programas de encontros anuais da International Studies Association (ISA) - principal agremiação internacional de acadêmicos de RI, com mais de seis mil membros e status consultivo na ONU - entre os anos de 2009 e 2013. Entre esses quatro anos, os encontros da ISA mobilizaram cerca de mil participantes, com mais de trezentas páginas de programação. Em 2009, nenhum dos trabalhos inscritos versava sobre Amazônia. Entre 2010 e 2013, houve um total de onze trabalhos sobre a região (ibid.)

Como parte de sua argumentação, Picq (2016, p. 8-9) sugere que a invisibilização da Amazônia nos estudos de RI se deve, em grande parte, ao caráter de dominação do Norte Global - notadamente dos EUA - sobre as pautas da disciplina. Embora estejamos de acordo com o diagnóstico da autora, nos inspiramos em seu trabalho para fazer uma rápida incursão a respeito da presença (ou não) da Amazônia na produção acadêmica em RI no Brasil, país do Sul Global e com mais de metade de seu território correspondendo à região amazônica.

Para tanto, optamos por uma breve análise dos Anais das três últimas edições do Encontro Nacional da Associação Brasileira de Relações Internacionais (ABRI), principal evento acadêmico de $\mathrm{RI}$ no país. Além disso, realizamos uma rápida pesquisa no acervo de três revistas acadêmicas de renome nas Relações Internacionais do Brasil, a saber: a revista Carta Internacional, publicação oficial da ABRI (Qualis B2); a revista Contexto Internacional, editada pelo Instituto de Relações Internacionais da PUC-Rio (Qualis A2); e a Revista Brasileira de Política Internacional, publicação do Instituto Brasileiro de Relações Internacionais (IBRI), sendo a mais antiga e melhor ranqueada entre as revistas acadêmicas da disciplina no país (Qualis A1). 
Os Encontros Nacionais da ABRI são realizados bianualmente, e têm as exposições de trabalhos dispostas de acordo com as sete áreas temáticas (ATs) da Associação: Análise de Política Externa; Economia Política Internacional; Ensino, Pesquisa e Extensão; História das Relações Internacionais e da Política Externa; Instituições e Regimes Internacionais; Segurança Internacional, Estudos Estratégicos e Política de Defesa; e Teoria das Relações Internacionais. No 5º Encontro Nacional da ABRI, em 2015, entre as centenas de trabalhos inscritos, apenas dois faziam referência à Amazônia, ambos na área temática de Instituições e Regimes Internacionais. Um deles propunha uma análise da paradiplomacia de duas cidades da Amazônia brasileira, Belém e Manaus, em seus esforços de cooperação internacional descentralizada (ROCHA, 2015). O outro, trazia uma análise do papel da Agência Nacional de Águas (ANA) do Brasil na liderança da cooperação técnica para gestão de recursos hídricos entre os países parte da Bacia Amazônica (DE SOUZA; VERSIEUX, 2015).

O 6을 Encontro Nacional da ABRI, realizado em 2017, novamente entre centenas de trabalhos inscritos, contou com oito envolvendo a Amazônia, dessa vez distribuídos em cinco áreas temáticas (ATs). Na AT de Análise de Política Externa, foram dois trabalhos. Um deles abordava o papel da Amazônia brasileira nos projetos de "conexão global" da China, propondo tangenciar as tensões ambientais envolvidas nesse processo (SILVEIRA, 2017). O outro, abordava a Amazônia como uma das regiões de destaque no planejamento da política externa venezuelana (WEBER, 2017). Na AT de Segurança Internacional, Estudos Estratégicos e Política de Defesa, houve um trabalho sobre a Amazônia, tangenciando projetos de monitoramento militar na região desde o período da redemocratização do Brasil (ANDRADE, 2017). Na AT de Teoria das Relações Internacionais, um trabalho propunha analisar as interações entre os Pelotões de Fronteira do Brasil e os povos indígenas da Amazônia a partir de um enfoque pós-estruturalista (ANTUNES, 2017).

Novamente, a AT de Instituições e Regimes Internacionais abarcou a maioria dos trabalhos sobre Amazônia propostos no Encontro de 2017. Foram três trabalhos, o primeiro dos quais propunha uma análise da paradiplomacia de governos estaduais da Amazônia brasileira frente ao Regime Internacional do Clima (SIQUEIRA, 2017). Os outros dois trabalhos da AT apontavam para direções mais heterodoxas nos estudos de RI. Um deles propunha uma análise de movimentos sociais transnacionais 
da Pan-Amazônia em suas resistências à construção de usinas hidrelétricas na região (SEQUEIRA, 2017). O outro, visava uma análise da construção política e social de territorialidades contra-hegemônicas na Amazônia (GONÇALVES, 2017). Por fim, um trabalho na AT de Ensino, Pesquisa e Extensão trazia alguns resultados do projeto de extensão Programa Globalizando, do curso de Rl da Universidade da Amazônia (UNAMA), dedicado à discussão de temas ligados à Amazônia em uma rádio universitária (UNAMA FM) (ALMEIDA; PINHEIRO; DA SILVA, 2017).

No $7^{\circ}$ Encontro Nacional da $A B R I$, realizado em 2019, houve cinco trabalhos sobre Amazônia. Um deles, na AT de Instituições e Regimes Internacionais, versava sobre a parceria entre um município na região amazônica do Pará (Curaçá - PA) com o Programa das Nações Unidas para o Desenvolvimento (PNUD), visando implementar projetos de Objetivos do Desenvolvimento Sustentável, notadamente na área de saneamento básico (FURTADO; CASTRO; NUNES, 2019). Outro, na AT de Teoria das Relações Internacionais, propunha problematizar diferentes imaginários fronteiriços no Brasil, dentre eles os de "deserto demográfico" e "internacionalização da Amazônia" (SUMMA, 2019).

Nesse Encontro, a maioria dos trabalhos sobre Amazônia ficou concentrada na AT de Segurança Internacional, Estudos Estratégicos e Política de Defesa, sendo todas as três contribuições de autores vinculados à Escola de Comando e EstadoMaior do Exército (ECEME). Um deles propunha pensar os países amazônicos em termos de seu potencial na "geopolítica ambiental" (DE SOUZA, 2019a). O outro, em via similar, buscava pensar na Organização do Tratado da Cooperação Amazônica (OCTA) à luz do conceito de "geopolítica ambiental" (DE SOUZA, 2019b). Finalmente, uma proposta versava sobre a importância do emprego de tecnologias de smart power para a garantia da soberania da Amazônia brasileira (ALMEIDA, 2019).

No que diz respeito às revistas acadêmicas de $\mathrm{Rl}$, uma rápida pesquisa no acervo da Carta Internacional, criada em 1993 e desde 2006 financiada pela ABRI, revelou a completa ausência de publicações sobre a Amazônia nas versões virtualmente disponíveis da revista (desde 2006). A revista Contexto Internacional, fundada em 1985, e com todos os seus volumes disponibilizados em versão digital, revelou um total de 5 (cinco) artigos envolvendo questões amazônicas. O primeiro deles, de 1996, traz uma discussão a respeito da globalização neoliberal como fonte tanto das causas da deterioração ambiental quanto de plataformas, ainda que 
limitadas, para confrontá-la através de políticas de desenvolvimento sustentável (MELLO, 1996). A Amazônia aparece como fonte de "estudos de caso" sobre ambas as questões.

Em 2011, houve dois artigos tangenciando temáticas da Amazônia, ambos sobre o impacto de migrações internacionais na região (ARAGÓN, 2011; SILVA, 2011). Em 2013, há um artigo analisando a paradiplomacia em municipalidades transfronteiriças da Amazônia, e a importância desse processo para impulsionar políticas de desenvolvimento na região (MOREIRA, 2013). Finalmente, já em 2018, temos um paper sobre o aumento dos investimentos externos diretos da China na região amazônica, principalmente no Brasil e Peru, problematizando a falta de um marco cooperativo comum na região para lidar com os desafios e oportunidades da aproximação chinesa à Amazônia (WEGNER; FERNANDES, 2018).

A Revista Brasileira de Política Internacional (RBPI) existe desde 1958, e também possui todas as suas edições disponíveis em versão digital. Uma consulta ao acervo virtual da Revista revelou um total de 8 (oito) publicações sobre a Amazônia, situadas entre 2007 e 2019. A primeira delas apresenta uma ampla contextualização da Amazônia Caribenha, composta por Guiana, Guiana Francesa, Suriname e Venezuela, tangenciando questões de inserção econômica, fluxos econômicos ilegais, migrações e geopolítica (presença da China e EUA) (PROCÓPIO, 2007). Dois anos depois, uma publicação do mesmo autor versava sobre o despreparo dos países amazônicos para implementar efetivamente normativas internacionais sobre direitos indígenas e políticas ambientais na região (PROCÓPIO, 2009).

Em edição de 2012, temos uma discussão a respeito do papel de municipalidades da Amazônia brasileira na governança global da questão climática, enfatizando o bem-sucedido caso de Manaus (INOUE, 2012). No ano seguinte, há um artigo versando sobre os desafios que a Pan-Amazônia traz para o Brasil a nível nacional, regional e internacional. Enfatiza-se a importância de expandir a presença do Estado para os rincões da Amazônia, de modo a assegurar uma extração sustentável de recursos na região e, principalmente, contrapor constantes ameaças à soberania brasileira que o autor nota na política internacional sobre a Amazônia (PENNA FILHO, 2013). Em 2014, há uma contribuição a respeito do pleito brasileiro frente à comissão da Convenção das Nações Unidas sobre o Direito do Mar, visando 
a integração do "cone do Amazonas" como parte da plataforma continental do país (MORE, 2014).

Em 2016, temos o já referenciado trabalho em que Manuela Picq propõe repensar as $\mathrm{Rl}$ a partir da Amazônia, enfatizando o papel essencial da região em processos históricos fundamentais às reflexões da disciplina, como a formação dos Estados-Nação na Europa e a Segunda Guerra Mundial (PICQ, 2016). O artigo de Picq marca uma inflexão que vai acompanhar todas as seguintes publicações sobre a Amazônia na RBPI: é de autoria de uma pesquisadora que escreve a partir de uma instituição acadêmica de fora do Brasil.

Em 2019, temos duas publicações da Revista tangenciando questões da Amazônia. A primeira delas traz uma análise de como os povos indígenas da região amazônica brasileira estão mobilizando a Resolução 169 da Organização Internacional do Trabalho (OIT) para pautar reivindicações por medidas ambientais mais efetivas frente ao governo do país (CHASE, 2019). O ponto da autora é demonstrar a difusão de normas na governança global, enfatizando como uma normativa que originalmente versa sobre direitos de populações tradicionais tem sido mobilizada para endossar políticas na área da governança ambiental (ibid.). Por fim, temos um artigo sobre a importância de atores subnacionais, não-estatais e transnacionais para a efetivação de uma governança global da adaptação climática, especificamente no estado do Acre (DE WIT; FREITAS, 2019).

Diante desse breve levantamento bibliográfico a respeito da produção acadêmica sobre Amazônia em Relações Internacionais no Brasil, cabe um olhar mais cuidadoso a respeito dos resultados obtidos. Diferentemente do argumento de Picq (2016, p. 1) sobre as RI de maneira geral, pensamos que seria mais adequado falar em uma "marginalização", mais do que uma invisibilização propriamente dita da Amazônia nas RI do Brasil. Há uma produção incipiente de trabalhos sobre a temática, ainda que ocupem uma posição marginal nas discussões da disciplina. Posto de outro modo, se Porto-Gonçalves (2017, p. 150, tradução nossa) identifica a Amazônia como uma "periferia da periferia", dada a "sua condição de região periférica dentro de países periféricos no sistema-mundo capitalista moderno e colonial", argumentamos que em termos de posição nas discussões acadêmicas em RI, a Amazônia está na 'periferia da periferia da periferia'. Mas que posição periférica é essa? Mais especificamente, quais são os 'lugares' da Amazônia nos estudos de Relações Internacionais no Brasil? 
Para responder a essa pergunta, buscamos sistematizar os resultados da pesquisa acima apresentada em quatro categorias principais: (1) com relação às áreas temáticas da ABRI; (2) com relação ao tema dos trabalhos; (3) com relação à região geográfica de produção; e (4) com relação ao tema dos trabalhos por região geográfica de produção.

Com relação à primeira divisão - por áreas temáticas da $A B R I$ - sintetizamos aqui o que já apresentamos no início da seção. Os 15 (quinze) trabalhos sobre Amazônia inscritos nas últimas três edições dos Encontros Nacionais da ABRI (2015, 2017 e 2019) encontram-se alocados em cinco das sete Áreas Temáticas (ATs) da Associação. A maioria (seis trabalhos) está na AT de Instituições e Regimes Internacionais. Segue a AT de Segurança Internacional, Estudos Estratégicos e Política de Defesa, com quatro trabalhos inscritos. As ATs de Análise de Política Externa e de Teoria das RI contam com dois trabalhos cada. Por fim, há um trabalho na AT de Ensino, Pesquisa e Extensão. Em uma primeira demarcação, portanto, um dos 'lugares' da Amazônia na produção acadêmica em RI no Brasil é a Área Temática de Instituições e Regimes Internacionais. Nela, concentram-se $40 \%$ (quarenta por cento) dos trabalhos sobre Amazônia inscritos nos últimos três Encontros da Associação (Ver Gráfico 1 abaixo).

GRÁFICO 1: Trabalhos em RI sobre a Amazônia apresentados em Encontros Nacionais da ABRI (2015-2019), por Área Temática.

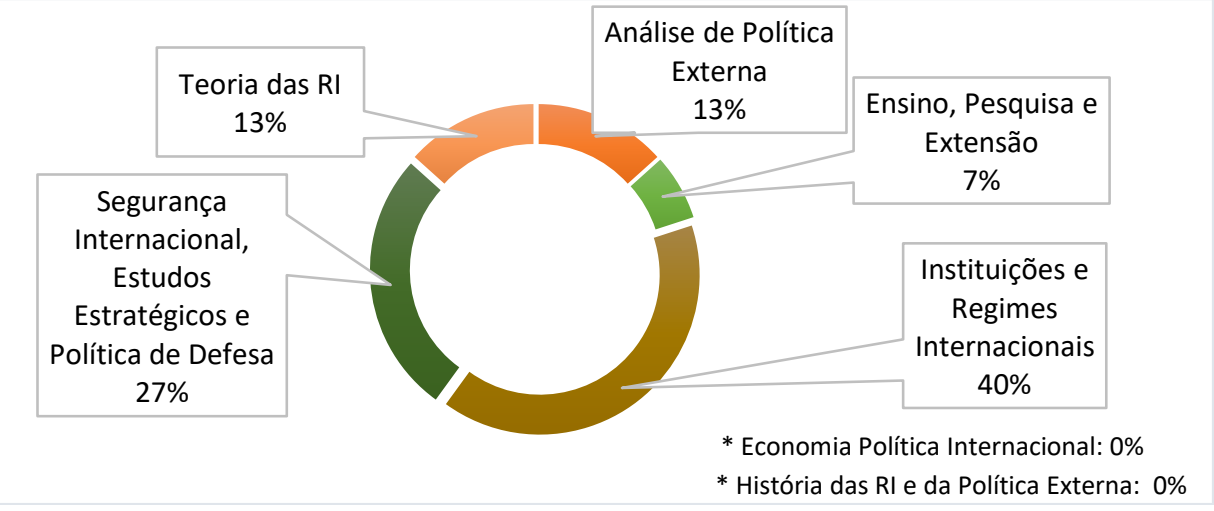

Elaboração do autor.

* História das RI e da Política Externa: 0\%

Além das Áreas Temáticas da ABRI, outro 'lugar' da Amazônia nas produções acadêmicas em RI no Brasil diz respeito aos "temas" dos trabalhos, incluindo tanto aqueles inscritos nos Encontros da Associação quanto os publicados nos periódicos Contexto Internacional e Revista Brasileira de Política Internacional. Em nossa 
delimitação dessas "divisões temáticas", um primeiro ponto de inspiração veio de contribuições que verificamos tanto em Carlos Porto-Gonçalves (2015, p. 65) quanto em Luís Aragón (2011, p. 74). Ambos os autores enfatizam que, nos estudos sobre a Amazônia, tendem a prevalecer duas formas centrais de representação. De um lado, a Amazônia enquanto território rico em recursos a serem explorados, logo, uma região a ser "desenvolvida". De outro lado, a Amazônia como uma região essencial para a manutenção do equilíbrio climático e da vida na Terra, portanto, como um território que deve ser "preservado".

Pensando na colocação dos autores, dividimos dois "temas" centrais presentes nos estudos da Amazônia nas RI aqui apresentados. O primeiro, diz respeito a visões da Amazônia enquanto fonte de recursos a serem mobilizados para fins da soberania e desenvolvimento do Estado. Aqui, inserimos contribuições mais voltadas para as áreas de política externa, economia política internacional, geopolítica e segurança internacional. Mais especificamente, incluímos nessa categoria os seguintes trabalhos: Almeida (2019); Andrade (2017); De Souza (2019a; 2019b); More (2014); Penna Filho (2013); Procópio (2007); Silveira (2017); Weber (2017) e Wegner; Fernandes (2018).

O segundo tema engloba perspectivas mais voltadas para a "preservação" da Amazônia, principalmente em estudos sobre cooperação internacional na área da governança climática. Pela ênfase dessas abordagens em redes que englobam atores estatais, subnacionais e não-estatais, optamos por denominar essa segunda categoria temática como de "preservação transnacional" da Amazônia, incluindo aí os estudos sobre a paradiplomacia na região. Aqui, situamos os seguintes trabalhos: Chase (2019); De Souza; Versieux (2015); De Wit; Freitas (2019); Furtado; Castro e Nunes (2019); Inoue (2012); Mello (1996); Moreira (2013); Procópio (2009); Rocha (2015) e Siqueira (2017).

A essas duas categorias, inspiradas nas colocações de Aragón (2011) e PortoGonçalves (2015), incluímos outras duas, referentes a áreas temáticas mais específicas das RI que identificamos nos trabalhos abordados. São elas: migrações e aquela que aqui propomos chamar de "territorialidades e resistências". Na categoria de migrações, inserem-se Aragón (2011) e Silva (2011). Na de "territorialidades e resistências", colocamos os trabalhos que partem de perspectivas não-convencionais em RI, seja em discussões epistemológicas, teóricas e conceituais, seja em uma 
ênfase analítica em comunidades locais da Amazônia e suas relações com seus territórios tradicionais. São eles: Almeida, Pinheiro e Da Silva (2017), Antunes (2017), Gonçalves (2017), Picq (2016), Sequeira (2017) e Summa (2019).

Outro elemento que pensamos ser interessante mobilizar para pensar nos 'lugares' da Amazônia nas produções acadêmicas em RI no Brasil diz respeito às regiões geográficas onde são produzidas essas contribuições. Nesse sentido, nota-se que a maior parte dos trabalhos são desenvolvidos em universidades ${ }^{3}$ nas regiões Centro-Oeste e Sudeste ${ }^{4}$, cada uma contribuindo com 8 (oito) dos 28 (vinte e oito) artigos aqui analisados. A essas, seguem a região Norte (7) e as contribuições produzidas em universidades estrangeiras (4). Nos acervos aqui pesquisados, consta ainda 1 (um) trabalho da região Sul e nenhum da região Nordeste. Abaixo, segue uma sistematização dos trabalhos analisados, considerando as divisões temáticas e regiões geográficas de produção (Tabela 1 ).

TABELA 1: Trabalhos sobre a Amazônia em RI apresentados em Encontros da ABRI (2015-2019) ou publicados nas revistas Contexto Internacional e Revista Brasileira de Política Internacional, distribuídos com relação à divisão temática e região geográfica das universidades dos autores.

\begin{tabular}{|lcc|cccccc|}
\hline & $\begin{array}{c}\text { Centro- } \\
\text { Oeste }\end{array}$ & Sudeste & Norte & Estrangeiros & Sul & Nordeste & Total \\
\hline Sivisões Temáticas & 3 & 6 & 1 & - & - & - & 10 \\
\hline Preservania/Desenvolvimento Transnacional & 4 & 1 & 2 & 3 & - & - & 10 \\
\hline $\begin{array}{l}\text { Territorialidades e } \\
\text { Resistências }\end{array}$ & 1 & 1 & 2 & 1 & 1 & - & $\mathbf{6}$ \\
\hline Migrações & - & - & 2 & - & - & - & $\mathbf{2}$ \\
\hline Total & $\mathbf{8}$ & $\mathbf{8}$ & $\mathbf{7}$ & $\mathbf{4}$ & $\mathbf{1}$ & - & $\mathbf{2 8}$ \\
\hline
\end{tabular}

Elaboração do autor.

\begin{abstract}
3 Todos os oito trabalhos da região Centro-Oeste foram produzidos no Instituto de Relações Internacionais da Universidade Nacional de Brasília (IREL/UnB). Os da região Norte dividem-se entre Universidade da Amazônia (UNAMA) (1), Universidade Federal do Amazonas (UFAM) (1), Universidade Federal do Pará (UFPA) (3) e Universidade Federal do Tocantins (UFT) (1), além de uma publicação conjunta de autores da UFPA e UNAMA. Na região sudeste, três dos oito trabalhos foram desenvolvidos pela Escola de Comando e Estado-Maior do Exército (ECEME). Os demais distribuemse entre o Instituto de Relações Internacionais da PUC-Rio (1), a PUC-Minas (1), a Universidade Estadual do Rio de Janeiro (UERJ) (1), a Universidade Federal Rural do Rio de Janeiro (UFRRJ) (1) e a Universidade Federal de São Paulo (UNIFESP). O trabalho da região sul foi desenvolvido na Universidade Federal do Rio Grande do Sul (UFRGS). Os trabalhos enviados de universidades estrangeiras vieram da European University Institute, da Universidade de Lisboa, da University of Massachusets e da Universidad San Francisco de Quito.

${ }^{4}$ É importante lembrar que essa região concentra a maioria dos cursos de Relações Internacionais no Brasil. Fonte: < http://www.funag.gov.br/ipri/index.php/teses-e-dissertacoes/47-estatisticas/111-cursosde-graduacao-e-pos-graduacao. Acesso em 11 abr. 2020.
\end{abstract}

Monções: Revista de Relações Internacionais da UFGD, Dourados, v.9, n.18, jul./dez. 
Frente a essa breve apresentação e sistematização dos trabalhos sobre Amazônia na produção acadêmica em RI no Brasil, podemos observar alguns dos 'lugares' que a Amazônia tem ocupado nos imaginários e construções analíticas da disciplina em nosso país. Para tanto, retomamos as quatro categorias que propusemos analisar. Em termos de (I) alocação nas Áreas Temáticas da ABRI, temos que dos 15 (quinze) trabalhos sobre Amazônia inscritos nas três últimas edições dos Encontros Nacionais da Associação, 6 (seis) foram alocados na AT de Instituições e Regimes Internacionais. Há também uma forte percepção da Amazônia como parte da agenda de Segurança Internacional, Estudos Estratégicos e Política de Defesa no Brasil, com 4 (quatro) de 15 (quinze) trabalhos situados nessa área.

Se considerarmos (II) as "divisões temáticas" que identificamos nessa seção (ver Tabela 1), nota-se que cerca de 2/3 (dois terços) dos trabalhos - considerando tanto os inscritos nos Encontros Nacionais quanto os publicados nos periódicos consultados - estão inseridos na dicotomia "soberania/desenvolvimento" vs. "preservação transnacional". Em termos de (III) regiões geográficas de produção dos 28 (vinte e oito) trabalhos aqui analisados, notamos uma primazia de publicações de universidades nas regiões Centro-Oeste (8) e Sudeste (8), seguidas da região Norte (7) e de universidades estrangeiras (4), além de uma única publicação vinda da região Sul (1). Nota-se, ainda, uma prevalência do Instituto de Relações Internacionais da Universidade Nacional de Brasília (UnB) nas produções sobre Amazônia em RI no Brasil, totalizando as 8 (oito) publicações da região Centro-Oeste.

Finalmente, se cruzarmos (IV) as divisões temáticas por região geográfica, temos que a maioria dos trabalhos no eixo de "soberania e desenvolvimento" (6/10) foram desenvolvidos em universidades na região Sudeste, sendo metade deles de autores da Escola de Comando e Estado-Maior do Exército (ECEME). Essa prevalência é digna de nota, por ser indício do imperativo de uma lógica militarizada sobre a Amazônia nos estudos e perspectivas da disciplina. Por mais importante que nos pareça, um maior aprofundamento nessa questão não cabe no escopo desse trabalho. Já entre os trabalhos no eixo da "preservação transnacional", há uma primazia de trabalhos desenvolvidos na região Centro-Oeste pelo IREL/UnB, com ênfase em abordagens à paradiplomacia. Nota-se também que a maioria dos 
trabalhos enviados de universidades estrangeiras (3/4) se inserem nesse eixo temático.

É importante notar que temos também nas $\mathrm{RI}$ do Brasil um conjunto de perspectivas que desafiam as abordagens mais convencionais da disciplina, buscando pensar a Amazônia a partir de suas comunidades tradicionais e das práticas políticas e sociais de resistência e significação dos territórios protagonizados por elas (seis dos vinte e oito trabalhos). É nesse conjunto de discussões, que procuram pensar a Amazônia em RI para além da soberania do Estado e do desenvolvimento capitalista, que visamos inserir a nossa contribuição nesse artigo, conforme segue na seguinte seção.

\section{Por uma outra inscrição da Amazônia nos estudos de RI no Brasil: reflexões sobre o Encontro Amazônia Centro do Mundo (EACM)}

Se decantarmos os resultados sistematizados na seção anterior, temos que a maioria da produção acadêmica sobre Amazônia em RI aqui avaliada se encaixa na dicotomia que marca grande parte das abordagens teóricas e políticas à região (PORTO-GONÇALVES, 2015, p. 65). De um lado, há as perspectivas que veem a Amazônia sob a ótica da soberania e desenvolvimento, ou seja, majoritariamente a partir de uma lógica de exploração da grande riqueza natural da região para fins de geração de lucro e poder. De outro lado, as que a veem como locus de uma imensa riqueza natural que deve ser preservada a partir de um esforço transnacional. Assim, como coloca Luís Aragón (2011, p. 74), "para alguns, a Amazônia representa uma grande reserva de recursos naturais ou capital natural, despovoada, que necessita ser ocupada; para outros [há na região] impactos ambientais negativos irreversíveis", que devem ser de alguma forma controlados.

Na perspectiva do geógrafo brasileiro Carlos Porto-Gonçalves (2015, p. 65), a quem se soma Manuela Picq (2016, p. 2), ambas as partes dessa forma dicotômica de representar a Amazônia revelam um olhar profundamente eurocêntrico - ou, como sugere Porto-Gonçalves (2017, p. 151), "eeuurocêntrico"5 - sobre a região. Isso porque, como acrescenta Maristella Svampa (2019, p. 40-41), impera uma lógica da

\footnotetext{
${ }^{5} \mathrm{O}$ autor propõe esse neologismo em texto no idioma espanhol, brincando com uma fusão entre "Estados Unidos" (E.E.U.U.) e "Eurocentrismo". Uma visão "eeuurocêntrica" seria, então, uma centrada no perspectivismo estadunidense e europeu.
} 

exercer algum tipo de controle (exploração ou preservação). Ignora-se, assim, a dimensão humana da Amazônia:

Em suma, a região continua sendo vista sob uma ótica eurocêntrica, ainda que com formulações distintas, que ignoram que a região não é só rio, floresta ou recursos minerais, mas sim uma região habitada há 11200 anos e que recebeu nos últimos cinco séculos outras contribuições, sobretudo camponesas, a maior parte de grupos sociais que fugiam da opressão do desenvolvimento colonial e seus latifúndios monocultores de exportação. Ali, na Amazônia, além das populações originárias, muitos grupos sociais foram buscar a liberdade, seja como cimarrones/quilombolas, seja como camponeses livres que souberam aproveitar-se criativamente da enorme produtividade biológica primária com a qual desenvolveram múltiplas culturas. Ao contrário do que se costuma afirmar, há um enorme acervo de conhecimentos a ser tomado em conta para um diálogo com outras matrizes de racionalidade [...] um verdadeiro diálogo de culturas (PORTOGONÇALVES, 2015, p. 66-67).

Tendo essa colocação em mente, consideramos, seguindo Picq (2016, p. 1114), que pensar as RI a partir da Amazônia pode trazer à tona questões desafiadoras e inovadoras tanto para refletir nas $\mathrm{RI}$ enquanto disciplina quanto na política mundial de modo geral. Assim:

Um primeiro bom motivo para pensar a política mundial a partir da Amazônia é pluralizar as RI. Uma RI Amazônica é fundamentalmente outra. Trazer a periferia para o centro vai nos permitir descolonizar a disciplina. Isso trará histórias não contadas para dentro das RI, e inevitavelmente recontará algumas de suas fundações conceituais. Isso complementará os entendimentos do que constitui as RI com novas perspectivas e histórias, renovará as agendas de pesquisa, expandirá as práticas globais. [...] Visões periféricas podem contribuir com conhecimentos alternativos para quebrar as camisas-de-força da disciplina (PICQ, 2016, p. 11, tradução nossa ${ }^{6}$, grifos nossos).

Nesse sentido, nossa proposta nessa seção é apresentar algumas breves reflexões a respeito de um caso que, pensamos, contribui para pensar as $\mathrm{Rl}$ a partir de marcos e perspectivas geralmente ignorados tanto na disciplina quanto nas visões hegemônicas da Amazônia que apresentamos acima. Trata-se do Encontro Amazônia Centro do Mundo (EACM), que contextualizaremos mais detalhadamente na seguinte subseção.

\footnotetext{
${ }^{6}$ No original: "The first good reason to think world politics from the Amazon is to pluralize IR. An Amazonian IR is fundamentally other. Bringing the periphery into the core will permit us to decolonize the discipline. It will bring untold stories into IR, and inevitably retell its conceptual foundations. It will complement new perspectives and histories to understandings of what constitutes $I R$, renew research agendas, expand global praxis. [...]. Peripheral visions can contribute alternative knowledge to break disciplinary straitjackets".
} 


\subsection{Encontro Amazônia Centro do Mundo (EACM) e a importância do "evento"} nas Relações Internacionais

O Encontro Amazônia Centro do Mundo (EACM) ocorreu nas imediações de Altamira, no Pará, em novembro de 2019. Para os fins de nossa discussão nesse artigo, pensamos ser importante dividir esse evento em duas partes: o Encontro na Terra do Meio e o Amazônia Centro do Mundo. A primeira parte é, aqui, a que mais nos interessa, pelo que consideramos o seu potencial de ampliação dos imaginários sobre política mundial e Relações Internacionais. Porém, consideramos ambas as partes como indissociavelmente entrelaçadas: é na segunda que muitas das deliberações feitas na primeira ganharam um espaço maior de debate e de efetivação enquanto pauta política. Por isso, consideramos ambas como partes de um único Encontro Amazônia Centro do Mundo, unidade de análise dessa seção.

Começamos, pois, pela primeira parte: o Encontro na Terra do Meio. Dada a própria natureza do Encontro, recente e relativamente 'isolada', nos fiaremos nos relatos das jornalistas Eliane Brum (El País), Joana Oliveira (El País) e Isabel Harari (Instituto Socioambiental), que estiveram presentes no Encontro. Em primeiro lugar, o Encontro foi organizado pela Associação de Moradores da Reserva Extrativista Rio Iriri (RESEX Iriri), em parceria com duas ONGs brasileiras: o Instituto Ibirapitanga e o Instituto Socioambiental (ISA). O objetivo era reunir jovens ativistas, lideranças e intelectuais trabalhando em torno da questão climática ao redor do mundo, e trazê-los para o "coração da Floresta Amazônica" para trocar experiências e discutir táticas e ideias (BRUM, 2019). Com efeito, como relata Harari (2019), entre os dias 11 e 16 de novembro de 2019, cerca de 70 pessoas se reuniram na RESEX Iriri, que fica na região conhecida como "Terra do Meio", no centro da Floresta Amazônica e na bacia do rio Xingu.

Entre os presentes, estavam jovens ativistas indígenas, das etnias kaiapó, yanomami, yudjá, xikrin e xipaya. Havia também jovens quilombolas da Amazônia brasileira, e representantes camponeses de RESEX da região. O Encontro contou ainda com a presença de jovens europeus ativistas nos movimentos Fridays for Future e Youth for the Climate. Estiveram presentes, também, representantes europeus do grupo Extinction Rebellion e do movimento russo Pussy Riot. Aos jovens ativistas, somaram-se velhas lideranças extrativistas, indígenas e quilombolas, como Socorro 
de Barbacena (comunidade quilombola de São Sebastião de Burajuba - PA), Davi Kopenawa (liderança Yanomami) e Seu Francisco de Assis (RESEX Iriri). Além disso, o grupo esteve composto por acadêmicos e jornalistas ativistas na questão amazônica, e por representantes das instituições organizadoras (BRUM, 2019; HARARI, 2019; OLIVEIRA, 2019a).

Para a realização do Encontro, o deslocamento foi uma questão fundamental. Como coloca Eliane Brum (2019), uma das idealizadoras do Encontro:

\begin{abstract}
Este é um encontro de descolonização. Por isso, não é um encontro na Europa nem um encontro nas capitais do Sudeste do Brasil. Deslocar o que é centro e o que é periferia é imperativo para criar futuro. [Assim], o encontro entre outros e outros acontece na floresta profunda, no lugar chamado Terra do Meio, na bacia do Xingu. Um mosaico de terras indígenas, reservas extrativistas ocupadas por beiradeiros, uma estação ecológica e um parque nacional. Os não índios, os não beiradeiros, os não quilombolas fizeram o gesto de se deslocar até o coração da floresta que é também o coração do planeta. Vieram para falar. Vieram principalmente para escutar. E sentir. Os rios, as árvores, seus povos humanos e não humanos. Reconhecem, com o deslocamento do corpo, a centralidade da floresta.
\end{abstract}

É paradigmático, nesse sentido, o caso das irmãs belgas Anuna de Wever e Joséphine Hoerée, que junto à amiga Adélaïde Charlier, cruzaram o Oceano Atlântico em um veleiro durante quarenta dias, para chegar à Amazônia sem emitir os poluentes que envolveriam um trajeto de avião (OLIVEIRA, 2019b). Novamente, a narrativa trazida por Eliane Brum (2019) acerca do Encontro vê nesse movimento uma poderosa carga metafórica. Nas palavras da autora:

É imensamente simbólico que as jovens ativistas climáticas Anuna De Wever e Adélaïde Charlier tenham escolhido alcançar a Amazônia de barco à vela desde a Europa. Não mais saltar sobre os mundos. Mas percorrê-los, por semanas, no gesto de alcançar o outro e encontrar a si mesmas. Desta vez, as caravelas são de descolonização.

É imensa a carga simbólica que o Encontro na Terra do Meio aporta, de maneira geral. Uma reunião de corpos não-brancos e brancos, jovens e anciãos, de distintos povos, dialogando em círculo entre iguais (em que pese suas diferenças) (HARARI, 2019; OLIVEIRA, 2019b). Fazendo-se entender, apesar das evidentes diferenças de culturas, idiomas, etnias e nacionalidades (OLIVEIRA, 2019a). Conforme relata Harari (2019), entre rodas de troca de experiências e falas científicas sobre a importância da Amazônia, os rituais espirituais a partir de sabedorias indígenas estiveram presentes desde a inauguração do Encontro. O simbolismo 
também esteve fortemente presente em outros momentos ao longo dos dias de reunião. Joana Oliveira (2019a), por exemplo, registra a seguinte cerimônia:

Davi Kopenawa lembrou dos 27 mil yanomamis que vivem em um território entre Roraima e Amazonas. "Cada aldeia tem dois pajés, que cuidam do universo, da onda do mundo. Mas nós já lutamos muito durante 20 anos. Agora, é a vez dos jovens, é a vez da juventude defender nossa Terra Mãe. Vocês vão construir outro tempo. Nós, lideranças do Brasil, vamos dar a flecha para vocês guerrearem com o homem grande", disse, enquanto entregava uma caneta aos jovens ativistas presentes. "Estou dando a flecha para vocês acertarem o coração do homem branco".

O encerramento da fase do Encontro na Terra do Meio também foi marcado por uma cerimônia de cunho mais ritualístico: uma "muvuca de sementes"7 para reflorestar uma antiga área de pecuária (HARARI, 2019). Com essa atitude:

O que antes era uma área destinada para a pecuária [...] vai compor uma mata tão diversa quanto os participantes do encontro. Todas as emissões do encontro foram neutralizadas com o plantio. A estimativa é que em 20 anos serão removidas da atmosfera 214 toneladas de carbono por hectare (HARARI, 2019).

Em nossa perspectiva, essa breve exposição do que foi o Encontro na Terra do Meio já suscita uma série de questões a respeito da solidariedade, ação política, sustentabilidade, interculturalidade, dentre tantas outras que consideramos essenciais para pensar na Amazônia, suas riquezas e seus povos. É com isso em mente que aqui propomos uma breve reflexão em $\mathrm{RI}$ a partir desse Encontro. A princípio, o caráter circunstancial desse evento, a ausência de vínculos do mesmo com instituições governamentais ou normativas internacionais mais abrangentes, ou mesmo da formulação de um projeto de ação concreta, poderiam sugerir ser contraintuitivo pensá-lo no âmbito das Relações Internacionais. Contudo, esse é justamente um dos caráteres que Manuela Picq (2016, p. 11-14) vê nos potenciais de se pensar as RI a partir da Amazônia: a perturbação dos marcos espaciais, temporais e normativos que comumente compõem os pressupostos analíticos da disciplina.

Propomos, pois, uma perturbação nesse sentido. E o fazemos, primeiramente, convidando para o debate as considerações da filósofa da ciência Isabelle Stengers (2018) a respeito da importância política dos "eventos"8. Como parte de sua

\footnotetext{
${ }^{7}$ Técnica de mistura de sementes para garantir a biodiversidade em projetos de plantio agroflorestais.

${ }^{8}$ Utilizamos aqui uma versão traduzida para o português das contribuições de Stengers. Na versão, traduziu-se o termo "événement", em francês, como "acontecimento". Utilizamos aqui o termo "evento", por pensarmos ser uma tradução mais apropriada e que faz mais sentido na argumentação proposta
} 
proposição provocativa de que 'o importante sempre está em outro lugar', Stengers (2018, p. 457) sugere que se dê mais atenção aos "eventos" por si mesmos, mais do que às "situações" onde geralmente se costuma buscar explicações para eles. Nas palavras da autora, "não se explica um [evento], mas o evento se explica a partir daquilo que terá sabido nele criar um lugar" (STENGERS, 2018, p. 457). Ela prossegue:

[...] um [evento] não possui em "si mesmo" o poder de fazer [evento], mas ele também não é apenas relativo à situação no sentido geral, como se pudéssemos deduzi-lo dessa situação (explicação sociológica). A situação não explica o [evento], ela poderia ter acolhido outros em seu lugar. Mas ela permite compreender a criação do lugar que é aquele deste [evento], isto é, compreender a maneira como este [evento] se situará. O [evento] se situa ativamente em relação à situação, ele intervém na situação. Ele se ampara em certos elementos da situação e cria um lugar, ou um ponto de vista, que permite caracterizá-la (STENGERS, 2018, p. 457, nota de rodapé 10).

Assim, o que nos importa não é tanto o "contexto" (nos termos de Stengers, a "situação") no qual se situa a realização do Encontro (o "evento"). Pensar nesses termos certamente abrangeria uma série de elementos mais facilmente legíveis pelas lentes das RI: a urgência da questão climática; a ascensão de governos de ultradireita na América Latina e a ameaça que representam para a Amazônia e seus povos tradicionais; os megaprojetos de infraestrutura e mineração na região; o papel das ONGs nesse cenário etc. Aqui, resistimos à tentação de seguir por esse caminho e propomos pensar na importância do Encontro ("evento") em si, nas interações que nele se deram e nas significações do contexto ("situação") que se articularam a partir dali. Apresentamos uma discussão mais detalhada nesse sentido na seguinte subseção, a partir dos resultados daquela que consideramos a segunda parte do Encontro Amazônia Centro do Mundo.

\subsection{O Manifesto Amazônia Centro do Mundo: repensando poder e resistência nas RI a partir da Amazônia}

Logo em seguida ao Encontro na Terra do Meio, as pessoas ali reunidas se dirigiram a Altamira, no Pará, para levar suas ideias ao evento maior Amazônia Centro do Mundo, conclamado por movimentos sociais do Xingu, organizações de povos da

pela autora. Por esse motivo, utilizamos colchetes quando o termo aparece nas citações que mobilizamos no texto.

Monções: Revista de Relações Internacionais da UFGD, Dourados, v.9, n.18, jul./dez. 
floresta e pela Universidade Federal do Pará (UFPA). Ali, entre os dias 17 e 19 de novembro de 2019 , se reuniram cerca de 300 pessoas, incluindo indígenas, ribeirinhos, agricultores, quilombolas, representantes de movimentos sociais, jovens ativistas pelo clima, acadêmicos e cientistas para "firmar seu compromisso em defesa da Amazônia" (HARARI, 2019). A ideia, segundo Brum (2019), era convocar "os brasis e os brasileiros a deslocarem seu corpo para o verdadeiro centro do país e do planeta para criar uma aliança pela Amazônia".

$\mathrm{Na}$ programação oficial do evento, constam 28 organizações promotoras ${ }^{9}$. Entre os oradores oficialmente registrados na Programação, estavam representantes dos pescadores, ribeirinhos, indígenas, quilombolas, pequenos agricultores e crianças; do movimento negro e movimentos ambientalistas; lideranças religiosas católicas e umbandistas; e acadêmicos, escritores e cientistas. As atividades previstas incluíam performances artísticas, plantios de árvores, uma marcha nas ruas de Altamira e a realização de Grupos de Trabalho (GTs) Temáticos ${ }^{10}$ para a elaboração de um "Manifesto do Centro do Mundo".

Feita essa breve contextualização, vemos na reflexão sobre o Encontro Amazônia Centro do Mundo, em ambas as suas partes, uma fonte potencial para se pensar na Amazônia em RI para além das visões dicotômicas eurocêntricas de "soberania/desenvolvimento vs. preservação transnacional". Trata-se de pensar na região como politicamente relevante para a política mundial justamente a partir dos sujeitos que Porto-Gonçalves (2015, p. 65-67) argumenta serem esquecidos pelas visões eurocêntricas: os povos da floresta, em sua agência política e suas interações e mobilizações sociais de resistência.

É sob essa ótica que olhamos para o Manifesto Amazônia Centro do Mundo, resultante das discussões no evento em Altamira - PA. Traçando também um paralelo

\footnotetext{
${ }^{9}$ Nomeadamente: a Associação dos Moradores da RESEX Iriri e da RESEX do Riozinho do Anfrísio; os Coletivos de Mulheres Negras Maria Maria, de Mulheres do Xingu e de Poetas Marginais; a Comissão de Justiça e Paz; a Conexão África Brasil; o Conselho Ribeirinho; os Fóruns da Amazônia Oriental e da Defesa de Altamira; as Fundações Tocaia e Viver, Produzir e Preservar; o Instituto Socioambiental; os Movimentos de Atingidos por Barragens; de Mulheres do Campo e Cidade e Xingu Vivo; a Oficina Território Livre; as Pastorais da Criança e da Juventude; a Prelazia do Xingu; a Rede Eclesial Pan-Amazônica (REPAM) Brasil e Xingu; o Sindicato dos Trabalhadores e das Trabalhadoras em Educação Pública do Pará (Sintepp) -Regional e Subsede; a Sociedade Paraense de Defesa dos Direitos Humanos e a Universidade Federal do Pará - Campus Altamira.

${ }^{10}$ Os GTs foram: (1) Falsas soluções que ameaçam a floresta; (2) Envolvimento para a Amazônia do Futuro; (3) Resistência das mulheres na Amazônia; (4) Juventudes e novos movimentos globais; (5) Povos da floresta e das águas; e (6) Educação para enfrentar o desenvolvimento predatório (ACM, 2019).
} 
com as discussões da subseção anterior, vemos no Manifesto a significação da "situação" (o contexto nacional e internacional que hoje ameaça a Amazônia e seus povos) a partir do "evento": o Encontro Amazônia Centro do Mundo (EACM) em suas duas partes, e os diálogos, reuniões e trocas de saberes que se deram nessa ocasião. Em nossa leitura do Manifesto, consideramos também um de nossos objetivos centrais propostos no artigo: o de seguir o convite de Manuela Picq (2016, p. 1) a "pensar as RI a partir da Amazônia". Nesse sentido, ressaltamos trechos do Manifesto que apontam diretamente em direção ao descentramento de pressupostos fundamentais da disciplina a partir de narrativas e referenciais amazônicos.

Um primeiro ponto a se destacar, nesse sentido, são as considerações do Manifesto a respeito da "soberania". Assim, temos que:

Nós, que nos unimos no centro do mundo, perguntamos: - Que soberania é esta em que uma empresa, a Norte Energia S.A., controla a água do rio Xingu para mover a Usina Hidrelétrica de Belo Monte? E, assim, tem poder de vida e morte sobres povos e ecossistemas inteiros?

E declaramos: Isso não é soberania, isso é ecocídio. E é também genocídio. Lutaremos contra todas as formas de morte (MANIFESTO ACM, 2019, grifo nosso).

Aqui, temos um questionamento direto à primeira parte do binômio "soberania/desenvolvimento". A partir da perspectiva dos povos da floresta, questionase uma soberania que, de um lado, relega a gestão dos recursos amazônicos a uma corporação de parceria público-privada. E que, de outro lado, tem um poder de "fazer morrer" (MBEMBE, 2016) sobre os povos que se colocam no caminho da soberania e do desenvolvimento. Tal perspectiva está em consonância com a de intelectuais que trabalham criticamente com questões da Amazônia, como o já mencionado geógrafo brasileiro Carlos Porto-Gonçalves (2017, p. 157), que aponta que a apropriação 'soberana' de espaços da Amazônia pelo Estado muitas vezes serve a fins desvinculados - e mesmo contrários - aos interesses das populações tradicionais da região.

Além da soberania, o Manifesto confronta frontalmente dois outros pilares das Relações Internacionais: o nacionalismo e o desenvolvimento. Sobre esses tópicos, temos que:

Nós, que nos unimos no centro do mundo, perguntamos: - Que nacionalismo é este que pretende entregar a Volta Grande do Xingu para uma mineradora canadense, a Belo Sun, explorar ouro e depois deixar como legado um cemitério tóxico para o Brasil? 
E declaramos:

Isso não é nacionalismo, é submissão. E é crime.

[...] Nós, que nos unimos no centro do mundo, perguntamos: - Que desenvolvimento para a Amazônia é este, que reduz milhões de espécies a soja, boi, minério, especulação de terras e obras de destruição? E declaramos:

Isso não é desenvolvimento. É predação. Lucro de poucos à custa da morte de muitos. Em vez de desenvolvimento, queremos envolvimento. Queremos Consulta Livre prévia e Informada. Queremos salvaguardas para os povos nas negociações climáticas. É a floresta e a economia da floresta que precisam crescer. [...] Lutaremos contra todas as formas de morte (MANIFESTO ACM, 2019, grifos nossos).

A conjunção crítica entre soberania, nacionalismo e desenvolvimento articulada no Manifesto é, em nossa perspectiva, um ponto de partida interessante para pensar em como a questão do "poder" nas RI pode ser problematizada a partir da Amazônia. Sabemos que, ao menos no mainstream teórico da disciplina, o "poder" é pensado sobremaneira em termos de afirmação da "soberania", muitas vezes a partir do controle exercido sobre os recursos materiais presentes no território dos Estados e da otimização destes em termos de "segurança" e "desenvolvimento", o que frequentemente envolve a mobilização de um certo "nacionalismo" (GUZZINI, 2005; WALKER, 2002, p. 64-65). As vozes da Amazônia ecoadas no Manifesto, contudo, parecem apontar para uma forte problematização dessa abordagem ao "poder". Esta seria, pois, uma abordagem reducionista, por ignorar as repercussões negativas (e muitas vezes perigosas) que a "soberania", o "nacionalismo" e o "desenvolvimento" relegam às populações periféricas; àqueles que, como os povos da floresta, muitas vezes estão às margens do Estado-Nação (ESCOBAR, 2004; KRISHNA, 2009).

Como lembra a socióloga argentina Maristella Svampa (2019, p. 40-41), em consonância com Porto-Gonçalves (2017, p. 156-157), a concretização de projetos de afirmação da soberania e promoção do desenvolvimento na Amazônia - isto é, projetos de "poder", nas concepções mais clássicas de RI - tem gerado intervenções tanto privadas quanto estatais que tendem a ameaçar os povos amazônicos e seus modos de vida tradicionais. Ainda seguindo Porto-Gonçalves (2017, p. 150) e Svampa (2019, p. 18-19), pode-se entender que as formas mais tradicionais de pensar o "poder" em RI - como uma articulação de "soberania" e "desenvolvimento" - são uma forma de legitimar uma tendência recorrente da economia-mundo capitalista: a expansão para territórios ainda inexplorados como forma de garantir a acumulação de capital mesmo frente às crises estruturais contemporâneas (HARVEY, 2005). 
Posto de outro modo, pensar criticamente a categoria de "poder" em RI a partir da Amazônia abre margens para pensá-la em termos de "colonialidade global": uma articulação entre poder do Estado e poder do capital que, em última instância, assegura a supremacia branca global, e segue perpetuando a exclusão e dominação sobre povos não-brancos em regiões periféricas do sistema-mundo moderno/colonial ${ }^{11}$ (ESCOBAR, 2004, p. 219-220). De fato, uma perspectiva semelhante pode ser observada no Manifesto, que faz referência à "supremacia branca e patriarcal [que] determinou a violência contra a Amazônia".

Se, de um lado, o Manifesto Amazônia Centro do Mundo nos oferece pontos de partida interessantes para pensar criticamente na categoria de "poder" em Relações Internacionais, de outro, também aponta para possíveis novas formas de pensar a "resistência" na política mundial. Consideramos os seguintes trechos providenciais nesse sentido:

\begin{abstract}
Nós somos aqueles e aquelas que não possuem a floresta. Nós somos floresta. Nós somos aqueles e aquelas que não destruímos a natureza. Nós somos natureza. Nós somos aqueles e aquelas que temos várias cores e formas e línguas e sexualidades e cosmologias e culturas. [...] Nossa aliança é pela descolonização de almas e mentes. Unidos no centro do mundo, somaremos o conhecimento dos intelectuais da floresta ao dos intelectuais da universidade; articularemos a experiência dos mais velhos à potência dos mais jovens; faremos o diálogo das identidades; respeitaremos todos os corpos. Sonhamos uma educação com a comunidade e não para a comunidade. Sabemos que só existirá floresta enquanto existirem os povos da floresta. Estaremos juntos, como múltiplos de um, nas lutas de todas as Amazônias. Onde a floresta sangrar, nós estaremos.

[...] Queremos amazonizar o mundo e amazonizar a nós mesmos. Liderados pelos povos da floresta, queremos refundar o que chamamos de humano e voltar a imaginar um futuro onde possamos viver (MANIFESTO ACM, 2019).
\end{abstract}

Em grande medida, o debate sobre "resistências" em RI pode ser dividido em duas categorias principais: de um lado, as abordagens que pensam em termos neogramscianos de grande movimentos sociais contra-hegemônicos articulados globalmente; de outro, abordagens pós-estruturalistas que veem a resistência em pequenos atos disruptivos cotidianos, rejeitando a ideia de grandes articulações globais (HIRST, 2015). Aqui, o Encontro Amazônia Centro do Mundo, em suas duas partes, nos dá elementos para pensar a resistência em RI a partir de um marco exterior

\footnotetext{
${ }^{11}$ Uma abordagem mais detalhada sobre o pensamento decolonial e seus conceitos de "colonialidade" e "sistema-mundo moderno/colonial" nas RI, embora de importância fundamental para se pensar "poder" e "resistência" nas formulações da disciplina, não cabe no escopo desse artigo. Para uma melhor contextualização a respeito, sugerimos a contribuição de Melody Fonseca e Ari Jerrems (2012).
} 
a essa dicotomia. Em nossa perspectiva, as resistências articuladas nesse "evento" não se encaixam nem na ideia de um grande movimento antissistêmico organizado, nem na de atos disruptivos antiessencialistas. Trata-se mais propriamente, pensamos, de uma rearticulação inovadora da ideia de "cosmopolítica".

Nesse ponto, não nos referimos à noção de "cosmopolitismo" própria das teorias liberais em RI que, como bem pontuam Errel Henderson (2013) e Marta Fernández (2014), carregam pressupostos eurocêntricos e racistas em suas proposições alegadamente 'universais'. Aqui, pensamos na "cosmopolítica" a partir de outro registro. Novamente, recorremos a Isabelle Stengers (2018, p. 463), cuja "proposição cosmopolítica" é justamente a negação de qualquer pretensão de universalização do gênero humano.

Para a autora, a cosmopolítica "trata-se justamente de desacelerar a construção desse mundo comum, de criar um espaço de hesitação a respeito daquilo que fazemos quando dizemos 'bom'” (STENGERS, 2018, p. 446). É o que coloca em suspenso qualquer pretensão de "bem comum" - como os clamores por "soberania" e "desenvolvimento" - chamando a atenção para as vozes de dissenso que insistem em apontar que o "realmente importante está em outro lugar" (ibid.). Nos termos de Bruno Latour (2014, p. 48), na "cosmopolítica", o cosmos (as múltiplas possibilidades de mundo, ou pluriverso) sempre evita o fechamento da política, ao passo em que a "política" (o dissenso, a luta por outras possibilidades) sempre impede o fechamento do "cosmos". Enquanto os cosmopolitas liberais sonhariam em habitar um "mundo comum", portanto, os cosmopolíticos estariam enfrentando a questão de em que pode vir a ser esse "mundo comum" a se coabitar (ibid.).

Tanto Stengers (2018) quando Latour (2014), em suas abordagens à cosmopolítica, parecem reticentes quanto à possibilidade de vocalização do cosmos, de representação política do dissenso. Nesse ponto, seguimos a abordagem da socióloga argentina Claudia Briones (2019, p. 101), que argumenta pela possibilidade de vocalização da agência e resistência cosmopolítica, contrapondo-a a práticas sistemáticas que tornam essas vocalizações inaudíveis e invisíveis. A questão, então, seria justamente dar espaço de fala e visibilidade para os grupos que promovem o diálogo e a solidariedade entre "subalternos" para contrapor estruturas de dominação e opressão (BRIONES, 2019, p. 118). Em perspectiva semelhante, autores como Arjun Appadurai (2011), Boaventura de Sousa Santos (2019) e Walter Mignolo (2000) 
têm falado, respectivamente, de uma cosmopolítica "de baixo para cima", "cosmopolítica subalterna" e de um "cosmopolitismo crítico" em chave decolonial.

É aí, pensamos, que se insere a contribuição do EACM para refletir sobre resistência nos marcos das Relações Internacionais. Há o reconhecimento da diversidade, da diferença, do elemento do cosmos: "somos aqueles e aquelas que temos várias cores e formas e línguas e sexualidades e cosmologias e culturas". Mas há, também, a perspectiva do debate e diálogo para a construção de um 'comum' a partir dessas diferenças. A soma de saberes da floresta com saberes intelectuais, da sabedoria dos mais velhos com a potência dos mais jovens, o "diálogo das identidades" para "refundar o que chamamos de humano e voltar a imaginar um futuro onde possamos viver" (MANIFESTO ACM, 2019). Nesse ponto, pensamos, é possível imaginar a potência do EACM na afirmação de uma "cosmopolítica da vida" contra a "geopolítica da morte" na Amazônia.

\section{Considerações Finais}

Ao longo da análise aqui proposta, identificamos que apesar de não estar invisível, a Amazônia segue um tema de reflexão periférico nas Relações Internacionais no Brasil. Em uma busca nos Anais dos três últimos Encontros Nacionais da ABRI, bem como nos arquivos de três importantes periódicos brasileiros de RI - a Carta Internacional, o Contexto Internacional e a Revista Brasileira de Política Internacional - encontramos um total de 28 (vinte e oito) produções sobre Amazônia: 15 (quinze) apresentações nos eventos na ABRI e 13 (treze) artigos publicados nos dois últimos periódicos. A partir desses resultados, propusemos pensar em quatro 'lugares' ocupados pela Amazônia nas produções brasileiras em RI, com base em (I) as áreas temáticas da $\mathrm{ABRI}$; (II) as divisões temáticas que identificamos em nossa revisão bibliográfica; (III) as regiões geográficas da produção acadêmica sobre o tema; e (IV) a divisão temática por região. Nesse movimento, identificamos a prevalência de trabalhos inscritos na Área Temática de Instituições e Regimes Internacionais da ABRI (6); bem como de produções desenvolvidas majoritariamente na região Centro-Oeste (8), no Instituto de Relações Internacionais da Universidade Nacional de Brasília (IREL/UnB), seguidas por universidades na região Sudeste (8) e Norte (7). 
Em termos de "divisões temáticas", notamos a prevalência daquelas circunscritas à dicotomia entre o eixo de "soberania/desenvolvimento", de um lado, e o de "preservação transnacional", do outro. No primeiro eixo, prevalecem as produções acadêmicas em universidades na região Sudeste (6 de 10). No segundo, há primazia das produções do IREL/UnB (4) - principalmente em estudos de paradiplomacia - seguidas das advindas de universidades estrangeiras (3). Além das divisões temáticas nessa dicotomia, há dois trabalhos inscritos no eixo de "migrações", ambos de autores da região Norte. Destacam-se também seis trabalhos no eixo que propusemos chamar de "territorialidades e resistências", no qual sugerimos inserir a nossa própria contribuição nesse artigo.

Nesse sentido, apresentamos uma reflexão sobre um evento específico - 0 Encontro Amazônia Centro do Mundo (EACM) - como forma de (re)pensar as RI a partir da Amazônia. Em nossas breves reflexões sobre esse "evento", pensamos ter identificado um potencial de problematização de formas mais ortodoxas de conceber o "poder" em abordagens da disciplina. Enquanto o "poder" tende a ser tradicionalmente pensado em RI em termos de "soberania", presença do Estado, extração de recursos e desenvolvimento econômico - pensados como fatores positivos - as perspectivas expostas no Manifesto Amazônia Centro do Mundo denunciam criticamente aspectos problemáticos desses fatores para os povos amazônicos. Ademais, apontam para outras dimensões do poder - como as de gênero, étnicas e raciais - ainda marginalmente reconhecidas como relevantes em RI. Além disso, argumentamos que o EACM também traz potencialidades para pensar diferentemente em "resistências" nas RI. Enquanto geralmente enquadra-se as resistências em termos de movimentos antissistêmicos organizados ou de pequenas rupturas cotidianas, o EACM destaca a potência do "evento" e da "cosmopolítica" como formas de valorizar as vozes e visões dos "povos da floresta" e buscar construir alianças entre saberes e subjetividades diversos rumo à construção de um 'comum'.

Por fim, gostaríamos de encerrar as reflexões do artigo a partir de uma metáfora identificada no próprio EACM: a "muvuca de sementes". Esperamos, com os resultados parciais apresentados ao longo do texto, ter contribuído com pequenas sementes que, se melhor cultivadas, têm o potencial de florescer em novas perspectivas e abordagens às RI a partir da Amazônia e de seus povos. Uma indicação nesse sentido seria um aprofundamento da revisão bibliográfica da 
produção acadêmica sobre Amazônia nas RI do Brasil. Evidentemente, o recorte aqui apresentado é bastante limitado, e merece uma expansão para mais periódicos, outros eventos, bancos de teses e dissertações etc. Outra possível indicação é um aprofundamento a respeito do próprio Encontro Amazônia Centro do Mundo e seu potencial de descentrar e rescentrar alguns dos principais pressupostos das $\mathrm{Rl}$, por exemplo, a partir da condução de rodas de conversa e entrevistas com representantes que estiveram presentes no Encontro. Por ora, esses direcionamentos aparecem como futuros eventuais caminhos de prosseguimento da pesquisa aqui exposta, rumo a um "(re) pensar as RI a partir da Amazônia" e explorar os potenciais de uma "cosmopolítica da Amazônia".

\section{Referências}

ALMEIDA, Mario; PINHEIRO, Bruna; DA SILVA, Gabriella. Programa Globalizando: O rádio como instrumento de extensão universitária em relações internacionais. Anais do $6^{\circ}$ Encontro Nacional da ABRI. Belo Horizonte, 2017. Disponível em: <https://tinyurl.com/y2rcx2en>. Acesso em: 12 abr. 2020.

ALMEIDA, Vanderson. O Emprego do Smart Power pelo Brasil e sua Influência na Garantia da Soberania sobre a Amazônia Brasileira. Anais do 70 Encontro Nacional da ABRI. Belo Horizonte, 2019. Disponível em: <https://tinyurl.com/y2qolw7x>. Acesso em: 12 abr. 2020.

AMAZÔNIA CENTRO DO MUNDO (ACM). Manifesto Amazônia Centro do Mundo. 2019a. Disponível em: <https://tinyurl.com/y45qslsw>. Acesso em: 12 abr. 2020.

AMAZÔNIA CENTRO DO MUNDO (ACM). Programação Amazônia Centro do Mundo. 2019b. Disponível em: <https://tinyurl.com/yylbdbsr>. Acesso em: 12 abr. 2020.

ANDRADE, Sérgio. A geopolítica do Brasil frente às novas adversidades do século XXI: as políticas de defesa do território nacional amazônico. Anais do $6^{\circ}$ Encontro Nacional da ABRI. Belo Horizonte, 2017. Disponível em: $<$ https://tinyurl.com/yxf7g7gij. Acesso em: 12 abr. 2020.

ANTUNES, Diego. A Interação entre Militares e Índios Na Fronteira Amazônica Brasileira: Uma Análise Pós-estruturalista sobre os Pelotões de Fronteira. Anais do $6^{\circ}$ Encontro Nacional da ABRI. Belo Horizonte, 2017.

APPADURAI, Arjun. Cosmopolitanism from Below: Some Ethical lessons from the Slums of Mumbai. The Salon, v. 4, p. 1-12, 2011.

ARAGÓN, Luis E. Introdução ao estudo da migração internacional na Amazônia. Contexto Internacional, v. 33, n. 1, p. 71-102, 2011. Disponível em: $<$ https://tinyurl.com/y6osytbd>. Acesso em: 12 abr. 2020. 
BRIONES, Claudia. Conflictividades interculturales: Demandas indígenas como crisis fructíferas. San José de Costa Rica: Editorial Universidad de Costa Rica (UCR), 2019.

BRUM, Eliane. Amazônia Centro do Mundo. El País (site), 15 nov. 2019. Disponível em: <https://tinyurl.com/y68xpwtc>. Acesso em: 12 abr. 2020.

CHASE, Veronika Miranda. The changing face of environmental governance in the Brazilian Amazon: indigenous and traditional peoples promoting norm diffusion. Revista Brasileira de Política Internacional, v. 62, n. 2, 2019. Disponível em: $<$ https://tinyurl.com/y28qya2v>. Acesso em: 12 abr. 2020.

DE SOUZA, Elany. Geopolítica Ambiental: perspectivas para os países amazônicos. Anais do 70 Encontro Nacional da ABRI. Belo Horizonte, 2019a. Disponível em: <shorturl.at/mwFLW>. Acesso em: 12 abr. 2020.

DE SOUZA, Elany. Mecanismos Regionais de Cooperação e Defesa da Amazônia: Revisitando os fundamentos da OTCA à luz da geopolítica ambiental. Anais do 70 Encontro Nacional da ABRI. Belo Horizonte, 2019b. Disponível em: $<$ https://tinyurl.com/y2qolw7x>. Acesso em: 12 abr. 2020.

DE SOUZA, Matilde; VERSIEUX, Bernardo. O Brasil na governança de recursos hídricos transfronteiriços: o papel da Agência Nacional de Águas na gestão integrada da Bacia Amazônica. Anais do $5^{\circ}$ Encontro Nacional da ABRI. Belo Horizonte, 2015. Disponível em: <https://tinyurl.com/y2qolw7x>. Acesso em: 12 abr. 2020.

DE WIT, Fronika Claziena Agatha; FREITAS, Paula Martins. Global climate adaptation governance in the Amazon through a polycentricity lens. Revista Brasileira de Política Internacional, v. 62, n. 2, 2019. Disponível em: <https://tinyurl.com/y6c8uoam>. Acesso em: 12 abr. 2020.

ESCOBAR, Arturo. Beyond the Third World: Imperial Globality, Global Coloniality and Anti-Globalisation Social Movements. Third World Quarterly, v. 25, n. 1, p. 207-230, 2004.

FERNÁNDEZ, Marta. O Cosmopolitismo Kantiano: Universalizando o lluminismo. Contexto Internacional, v. 36, n. 2, p. 417-456, 2014. Disponível em: $<$ https://tinyurl.com/y2efumxt>. Acesso em: 15 fev. 2020.

FONSECA, Melody; JERREMS, Ari. Pensamiento decolonial: ¿una "nueva" apuesta en las Relaciones Internacionales? Relaciones Internacionales, v. 9, p. 103-121, 2012. Disponível em: <https://repositorio.uam.es/handle/10486/668333>. Acesso em: 12 abr. 2020.

FURTADO, Lourdes; CASTRO, Raylson; NUNES, Thainá. Objetivo Global 6 (ODS$\mathrm{ONU}$ ) e as discussões sobre Políticas Públicas de Saneamento e Água no município de Curuçá, Pará. Anais do 70 Encontro Nacional da ABRI. Belo Horizonte, 2019. Disponível em: <https://tinyurl.com/yxta7y5c>. Acesso em: 12 abr. 2020. 
GONÇALVES, Marcela Vecchione. Sentindo e Pensando o Território: Tecendo Redes e Re-Existindo através da Natureza para além das Zonas de Sacrifício na PanAmazônia. Anais do $6^{\circ}$ Encontro Nacional da ABRI. Belo Horizonte, 2017. Disponível em: <https://tinyurl.com/y5v2fpke>. Acesso em: 12 abr. 2020.

GUZZINI, Stefano. The Concept of Power: a Constructivist Analysis. Millennium: Journal of International Studies, v. 33, n. 3, p. 495-521, 2005.

HARARI, Isabel. Amazônia, a floresta que pulsa em nós. El País (site), 20 dez. 2019. Disponível em: <https://tinyurl.com/y6gmwkxg>. Acesso em: 12 abr. 2020.

HARVEY, David. O novo imperialismo. São Paulo: Edições Loyola, 2005.

HENDERSON, Errol A. Hidden in plain sight: racism in international relations theory. Cambridge Review of International Affairs, v. 26, n. 1, p. 71-92, 2013. Disponível em: <https://tinyurl.com/y4tl9r6g>. Acesso em: 12 abr. 2020.

HIRST, Aggie. Derrida and Political Resistance: The Radical Potential of Deconstruction. Globalizations, v. 12, n. 1, p. 6-24, 2015. Disponível em: $<$ https://tinyurl.com/y236s46v>. Acesso em: 12 abr. 2020.

INOUE, Cristina. Governance of global climate change in the Brazilian Amazon: the case of Amazonian municipalities of Brazil. Revista Brasileira de Política Internacional, v. 55, p. 170-189, 2012. Disponível em: <https://tinyurl.com/y2k2epwh>. Acesso em: 12 abr. 2020.

KRISHNA, Sankaran. Globalization and Postcolonialism: Hegemony and Resistance in the Twenty-First Century. Lanham: Rowman \& Littlefield, 2009.

LATOUR, Bruno. ¿El cosmos de quién? ¿Qué cosmopolítica?: Comentarios sobre los términos de paz de Ülrich Beck. Revista Pléyade, v. 14, p. 43-59, 2014.

MBEMBE, Achille. Necropolítica: biopoder, soberania, estado de exceção, política da morte. Arte \& Ensaios, v. 32, p. 123-151, 2016.

MELLO, Valérie de Campos. Globalização e Desenvolvimento Sustentável: o Caso da Amazônia Brasileira. Contexto Internacional, v. 18, n. 2, p. 291-328, 1996.

MIGNOLO, Walter. The many faces of cosmo-polis: Border thinking and critical cosmopolitanism. Public culture, v. 12, n. 3, p. 721-748, 2000.

MORE, Rodrigo Fernandes. Considerations about the recommendations of the Commission on the Limits of the Continental Shelf on the Amazon fan. Revista Brasileira de Política Internacional, v. 57, n. 1, p. 117-142, 2014. Disponível em: <https://tinyurl.com/y4kjxxdo>. Acesso em: 12 abr. 2020.

MOREIRA, Paula Gomes. Governos Subnacionais Amazônicos: Novos Padrões de Relacionamento na Conjuntura Internacional Contemporânea. Contexto Internacional, v. 35, n. 1, p. 33, 2013. 
OLIVEIRA, Joana. Encontro global no coração da Amazônia tenta adiar o fim do mundo. El País (site), 16 nov. 2019a. Disponível em: <https://tinyurl.com/y2xgwnqd>. Acesso em: 12 abr. 2020.

OLIVEIRA, Joana. Geração 'Greta' da Amazônia luta por sobreviver antes de falar em mudança climática. El País (site), 26 nov. 2019b. Disponível em: $<$ https://tinyurl.com/y506mzw5>. Acesso em: 12 abr. 2020.

PENNA FILHO, Pio. Reflexões sobre o Brasil e os desafios Pan-Amazônicos. Revista Brasileira de Política Internacional, v. 56, n. 2, p. 94-111, 2013. Disponível em: $<$ https://tinyurl.com/yyp47veu>. Acesso em: 12 abr. 2020.

PICQ, Manuela. Rethinking IR from the Amazon. Revista Brasileira de Política Internacional, v. 59, n. 2, p. 1-17, 2016. Disponível em: <https://tinyurl.com/y2kc5ols >. Acesso em: 12 abr. 2020.

PORTO-GONÇALVES, Carlos Walter. Amazônia enquanto acumulação desigual de tempos: Uma contribuição para a ecologia política da região. Revista Crítica de Ciências Sociais, n. 107, p. 63-90, 2015. Disponível em: <https://tinyurl.com/y58326z6>. Acesso em: 12 abr. 2020.

PORTO-GONÇALVES, Carlos Walter. Tensiones territoriales actuales. Nueva Sociedad, n. 272, p. 150-159, 2017.

PROCÓPIO, Argemiro. A Amazônia Caribenha. Revista Brasileira de Política Internacional, v. 50, n. 2, p. 97-117, 2007. Disponível em: <https://tinyurl.com/y5rg76f4>. Acesso em: 12 abr. 2020.

PROCÓPIO, Argemiro. Gulliver na Amazônia e as aventuras do indigenismo nas Relações Internacionais. Revista Brasileira de Política Internacional, v. 52, n. 2, p. 133-154, 2009. Disponível em: <https://tinyurl.com/y6l7|xdc>. Acesso em: 12 abr. 2020.

ROCHA, William Monteiro. Relações Internacionais de Cidades Amazônicas: Projeção internacional e Desenvolvimento local de Belém e Manaus. Anais do $5^{\circ}$ Encontro Nacional da ABRI. Belo Horizonte, 2015. Disponível em: $<$ https://tinyurl.com/yxb2cpvv>. Acesso em: 12 abr. 2020.

SANTOS, Boaventura de Sousa. O fim do império cognitivo: A afirmação das epistemologias do Sul. Belo Horizonte: Autêntica, 2019.

SEQUEIRA, João Élbio. Entre o Internacional e o Doméstico: os governos estaduais amazônicos e o desafio de implementar as decisões do Regime Internacional do Clima. Anais do $6^{\circ}$ Encontro Nacional da ABRI. Belo Horizonte, 2017. Disponível em: <https://tinyurl.com/y5v2fpke>. Acesso em: 12 abr. 2020. 
SILVA, Sidney Antônio da. Migração internacional recente no amazonas: o caso dos Hispano-americanos. Contexto Internacional, v. 33, n. 1, p. 155-177, 2011. Disponível em: <https://tinyurl.com/yyxvfv7r>. Acesso em: 12 abr. 2020.

SILVEIRA, Laura. Os laços e os traçados da China no Brasil. Novas perspectivas de conexão global. Anais do $6^{\circ}$ Encontro Nacional da ABRI. Belo Horizonte, 2017. Disponível em: <https://tinyurl.com/y55vphk9>. Acesso em: 12 abr. 2020.

SIQUEIRA, Carlos Eduardo. Entre o Internacional e o Doméstico: os governos estaduais amazônicos e o desafio de implementar as decisões do Regime Internacional do Clima. Anais do $6^{\circ}$ Encontro Nacional da ABRI. Belo Horizonte, 2017. Disponível em: <https://tinyurl.com/y5v2fpke>. Acesso em: 12 abr. 2020.

STENGERS, Isabelle. A proposição cosmopolítica. trad. Raquel Camargo; Stelio Marras. Revista do Instituto de Estudos Brasileiros, n. 69, p. 442, 2018. Disponível em: <https://tinyurl.com/y206rh5v>. Acesso em: 12 abr. 2020.

SUMMA, Renata. Práticas de Fronteira e Representações do Brasil em disputa. Anais do 70 Encontro Nacional da ABRI. Belo Horizonte, 2019. Disponível em: $<$ https://tinyurl.com/y6ezu7ab>. Acesso em: 12 abr. 2020.

SVAMPA, Maristella. Las fronteras del neoextractivismo en América Latina: conflictos socioambientales, giro ecoterritorial y nuevas dependencias. San José de Costa Rica: Editorial Universidad de Costa Rica (UCR), 2019.

WALKER, R.B.J. The Subject of Security. In: KRAUSE, Keith; WILLIAMS, Michael C. (orgs.). Critical Security Studies: Concepts and Cases. Londres: Taylor \& Francis eLibrary, 2002, p. 61-83.

WEBER, Leonardo. Política Externa e Integração Regional: o projeto da Venezuela para a América Latina. Anais do $6^{\circ}$ Encontro Nacional da ABRI. Belo Horizonte, 2017. Disponível em: <https://tinyurl.com/y4sch54a>. Acesso em: 12 abr. 2020.

WEGNER, Rubia Cristina; FERNANDES, Marcelo Pereira. The Amazon and the Internationalisation of Chinese Companies. Contexto Internacional, v. 40, n. 2, p. 361385, 2018. Disponível em: <https://tinyurl.com/y5cyfwa5>. Acesso em: 12 abr. 2020. 